\title{
Redomesticidad y encarcelamiento femenino en el sistema penitenciario español. Los Módulos de Respeto
}

\section{Ana Ballesteros Pena}

Universidad de Barcelona. Departamento de Sociología

a.ballesterospena@gmail.com

Recepción: 08-06-2016

Aceptación: 12-09-2016

\section{Resumen}

En el contexto del estudio de las continuidades y mutaciones en la ejecución penal femenina en el Estado español en el siglo xxi, en el presente artículo, se pretende abordar la forma que adoptan en la actualidad determinados rasgos históricamente presentes en el encarcelamiento femenino. Para este ejercicio, se ha tomado como estudio de caso los denominados Módulos de Respeto (MdR), con presencia de mujeres en tres centros penitenciarios. La metodología empleada en la investigación ha sido de corte cualitativo y se ha concretado esencialmente en la realización de observación directa no participante y más de 100 entrevistas a mujeres encarceladas y a profesionales de equipos técnicos y directivos, así como a responsables y exresponsables políticos de instituciones penitenciarias. Mediante el análisis de las dinámicas cotidianas y prácticas de los MdR de mujeres, el artículo demuestra la pervivencia de un modelo de domesticidad reforzado («estrategia de la redomesticidad») que, sobre la base de un fortalecimiento de las pautas de vigilancia y control, no hace más que perpetuar un tratamiento diferencial y más duro para las mujeres encarceladas. Este modelo interacciona, en el contexto de las formas de penalidad neoliberal, con ciertos mecanismos de reconstrucción de las identidades, lo que provoca mutaciones que apuntan hacia formas más sutiles de aplicación del castigo en los sistemas penitenciarios contemporáneos.

Palabras clave: disciplina; vigilancia; ejecución penal; prisiones; mujeres presas; castigo; neoliberalismo penal; criminología feminista 
Abstract. Re-domesticity and Female Imprisonment in the Spanish Penitentiary System: Respect Modules

In the context of the study of continuities and mutations in female penal enforcement in 21st Century Spain, this article aims to examine the form that certain historic and persistent characteristics of female incarceration have adopted today. To this end, "Respect Modules" (Módulos de Respeto or MdR in Spanish) for women in three prisons have been taken as a case study. Qualitative methodology was used, essentially consisting in nonparticipatory direct observation and more than 100 interviews with incarcerated women, professionals of technical and management teams, as well as political authorities and former authorities in charge of the prison system. By analyzing the daily dynamics and practices of women's MdRs, the article shows how a model of reinforced domesticity ("strategy of re-domesticity") has persisted which, through strengthening surveillance and control, only perpetuates the differential and tougher treatment of incarcerated women. In the context of neoliberal forms of penality, this model interacts with certain mechanisms to reconstruct subjectivities, causing mutations that point to more subtle forms of punishment in contemporary prison systems.

Keywords: discipline, surveillance, penal enforcement, prisons, women in prison, punishment, neoliberal penality, feminist criminology

\section{Sumario}

1. Introducción

2. Metodología

3. Disciplina, domesticidad y moralización: Las claves del encarcelamiento femenino a lo largo de la historia
4. La estrategia de la redomesticidad en los MdR de mujeres

5. Conclusiones y futuras líneas de investigación

Referencias bibliográficas

\section{Introducción}

Durante las dos legislaturas que abarcan el periodo 2004 a 2011, las autoridades penitenciarias del entonces gobierno socialista, encabezadas por Mercedes Gallizo, introdujeron un conjunto de medidas en el sistema penitenciario español, con el fin de avanzar hacia una mayor aplicación del reglamento penitenciario vigente (1996). A grandes rasgos, las actuaciones implementadas se orientaban hacia tres grandes áreas: en primer lugar, el impulso del tratamiento mediante la puesta en marcha de programas de intervención dirigidos a grupos específicos de población penitenciaria. En este ámbito, se diseñaron iniciativas a través del trabajo coordinado con universidades, personas expertas y profesionales y se potenciaron programas que se venían desarrollando en determinados centros penitenciarios, como los Módulos de Respeto (en adelante, MdR) o las Unidades Terapéuticas y Educativas (UTE). En segundo lugar, se trató de visibilizar e impulsar el trabajo de las entidades del tercer sector en el contexto penitenciario y se creó el Consejo Social Penitenciario (junto 
con consejos locales en cada prisión), órgano consultivo y de relación entre las asociaciones y ONG y la Institución Penitenciaria. Por último, se trató de potenciar el medio abierto mediante el impulso de las salidas programadas y la potenciación de los centros de inserción social (CIS), entre otras iniciativas (Ballesteros y Almeda, 2015: 169).

Una de los programas que tuvo una mayor expansión durante ese periodo fueron los denominados Módulos de Respeto. Esta iniciativa surgió en 2001, en la cárcel de Mansilla de las Mulas (León) para población penitenciaria masculina y, tal y como recoge el Manual sobre Módulos de Respeto de la Secretaría General de Instituciones Penitenciarias (2011), se define como una unidad de separación interior de un centro penitenciario, es decir, en principio, cada MdR se implantaría de forma autónoma en el espacio físico que hoy representa un módulo penitenciario al uso. La participación en el mismo es, en principio, voluntaria ${ }^{1}$, a partir de la firma de un "contrato terapéutico», que lleva implícita la aceptación de las normas del módulo. Estas normas regulan las siguientes áreas: personal, referente a higiene, aspecto, vestuario y cuidado de la celda; de cuidado del entorno (tareas del módulo) relativo a la utilización y al mantenimiento de los espacios comunes; de relaciones interpersonales, incluyendo todas las interacciones del sujeto con otras personas internas, con funcionarios, terapeutas y personal del exterior, y de actividades, en la que se regula la programación de actividades de cada persona interna, independientemente de las tareas del módulo que le correspondan a su grupo, de carácter obligatorio, que comprende todos los días de la semana y todas las horas del día, en la que se determinan qué actividades debe realizar en cada momento y se planifican los tiempos de ocio (Cendón et al., 2011: 14). Tal y como continúa el manual, el modelo se estructura en tres ejes: un sistema de organización de grupos, que son los encargados de realizar la limpieza y el mantenimiento de las zonas comunes; un procedimiento inmediato de evaluación mediante un sistema de imposición de negativos que repercuten en las tareas que el grupo realiza semanalmente y, por último, una estructura de participación de población interna mediante órganos que se reúnen con diferente periodicidad, entre los que destacan una asamblea diaria, una asamblea de responsables y ciertas comisiones (Cendón et al., 2011: 15).

El modelo de grupos parte de la idea de que el contacto constante con diversos colectivos con normas y costumbres respetadas y conocidas por sus miembros y cuyo incumplimiento es sancionado por el refuerzo y el castigo social constituye una característica esencial de una situación social normalizada (Cendón et al., 2011: 39). Sobre esta base, el MdR busca crear una situación artificial que siga estas mismas pautas y que, a través de la presión del grupo y mediante el reconocimiento de la figura del responsable, garantice el cumplimiento de las normas del módulo y el mantenimiento de las zonas comunes.

1. El carácter voluntario de este módulo plantea algunas excepciones en el caso de las mujeres que se detallarán en los apartados siguientes, tal y como apuntan Ballesteros y Almeda (2015). 
Para ello, se realiza una distribución de las personas internas en grupos, con la designación de un responsable, que se encargan de las tareas de limpieza de un área y del mantenimiento de las zonas comunes del módulo y cuya selección se realiza semanalmente, de modo que se encuentra supeditada a las valoraciones individuales obtenidas por los miembros del grupo. Esto es, el grupo cuyos miembros acumulen un mayor número de valoraciones negativas tendrá que realizar las tareas más gravosas dentro del módulo. Asimismo, los integrantes y las integrantes de los diferentes grupos tienen la obligación de exigir que se cumplan las normas de utilización de las diversas zonas al resto de las personas en el módulo (Cendón et al., 2011: 44-45).

La evaluación, por su parte, adopta varias modalidades (diaria, semanal, etc.) y sistemas de clasificación (negativo, favorable, desfavorable, etc.), aunque su elemento más característico lo constituye el negativo o «la evitación del mismo», mediante la adecuación a las normas y la planificación del módulo. El objetivo es que la persona interna se sienta legitimada para exigir a los demás el cumplimiento de las normas vinculadas a la zona de responsabilidad de su grupo. Además de este objetivo, el sistema de evaluación permite la obtención de información para la toma de decisiones sobre las personas internas y la elaboración de informes para otras instancias, entre otras funcionalidades (Cendón et al., 2011: 69).

Los órganos de participación tienen diferentes modalidades y finalidades: la Asamblea General (o reunión diaria) se realiza con presencia del educador o la educadora, mientras la Asamblea de Responsables (o reunión semanal) no cuenta con la presencia de ningún profesional, sino que es una reunión abierta con participación obligatoria de las personas responsables y voluntaria del resto de personas internas. Por otro lado, la Comisión de Convivencia, formada por un grupo de personas presas previamente seleccionadas, tiene la finalidad de resolver los conflictos que puedan surgir, a la vez que «avisar, reprender o intervenir con determinados sujetos cuya inadaptación al módulo está perjudicando la convivencia normalizada» (Cendón et al., 2011).

Los objetivos generales que explícitamente se plantea este programa incluyen la creación de un clima social normalizado que sirva de marco a los programas de tratamiento, la ruptura de la dinámica carcelaria a través de la modificación de las relaciones de grupo y el desarrollo de programas de tratamiento en hábitos, valores y actitudes (Cendón et al., 2011: 34-35). Aparte de estos objetivos generales, también se identifican un conjunto de objetivos específicos, estructurados según las áreas anteriormente mencionadas, entre los que se pueden destacar: el desarrollo y el mantenimiento de hábitos de higiene personal; el fomento del cuidado y de la organización del espacio personal; la implicación en el cuidado del entorno; la asunción de responsabilidades y el desarrollo de hábitos de participación y diálogo, y la erradicación de la violencia y la agresividad y la resolución de problemas y conflictos por vías socialmente aceptables (Cendón et al., 2011: 35). Para finalizar, el programa de MdR recoge un conjunto de objetivos operativos vinculados con la realización concreta de actividades cotidianas y que, entre 
otras, serán objeto de evaluación constante por parte del personal de vigilancia y el equipo técnico. A modo de ejemplo, respecto al mantenimiento de las celdas, se especifica que la celda se barre y se friega todos los días tantas veces como sea necesario, puesto que debe estar siempre en perfecto estado de orden y limpieza; la cama debe estar bien hecha, con la colcha reglamentaria colocada, y que el inodoro, el lavabo y la ducha deben estar limpios y brillantes.

En el marco del impulso de los programas de tratamiento en la primera legislatura socialista (2004-2008), y como resultado del contacto de las autoridades con esta iniciativa en una de las visitas a la prisión de Mansilla de las Mulas (León), este modelo se empieza a generalizar en el sistema penitenciario a partir del año 2005. La popularidad de este programa se ha incrementado de tal forma que se ha llegado a la aprobación de la Circular 18/2011, que plantea la implantación de un sistema gradual de módulos en función de su nivel de exigencia, de tal forma que en todos se vayan incorporando las características de los MdR.

Es necesario apuntar que, a pesar de la descripción detallada que recoge el manual de las características y el funcionamiento de los $\mathrm{MdR}$, el conocimiento directo del sistema penitenciario español permite comprobar cómo cada centro penitenciario ha asumido y adaptado las normas recogidas en el manual de una forma particular. Las diferencias en la periodicidad de las asambleas, en la selección de responsables de grupos o la implantación del programa de $\mathrm{MdR}$ en coexistencia con las condiciones en las que habitualmente funcionan los módulos ordinarios son algunas de las principales modificaciones operadas (Ballesteros y Almeda, 2015: 178).

En paralelo a las medidas arriba mencionadas, uno de los grupos de población penitenciaria que recibirá atención especial, sobre todo a partir de la segunda legislatura 2008-2011, será el de las mujeres presas. A partir de la constatación de la discriminación que venían sufriendo de forma tradicional en el sistema penitenciario y que se recogía en diversas investigaciones e informes elaborados desde fines de la década de 1990 en el Estado español — sin ánimo de exhaustividad, se destacan: Equipo Barañí (2001, 2007), Almeda (2002, 2003); Manzanos y Balmaseda (2003); Miranda, Martín y Vega (2005); Naredo (2004); Ribas, Almeda y Bodelón (2005); Proyecto MIP (2005); Defensor del Pueblo Andaluz (2006); Yagüe (2006, 2012); Almeda y Bodelón (2007); Igareda (2007); Miranda y Martín (2007); Ballesteros (2010); Castillo y Ruiz (2010); Francés y Serrano (2011); Del Val y Viedma (2012); Mapelli (dir.) (2012); Mapelli, Herrera y Sordi (2013); Gea, Domínguez y Sádaba (2014); De Miguel (2016)— desde la Secretaría General de Instituciones Penitenciarias, se decide nombrar como subdirectora general de Tratamiento y Gestión Penitenciaria a una profesional del ámbito carcelario, conocedora directa de la realidad de las mujeres presas y a la que se da el encargo de impulsar, en el ámbito de sus responsabilidades, los temas en materia de igualdad y atención a las mujeres encarceladas. Auspiciada por el impulso general de las políticas de igualdad de género que se estaban llevando a cabo en aquellos años en el conjunto del Estado español y 
que se materializó en la aprobación de importantes textos normativos como la Ley Orgánica 3/2007, de 22 de marzo, para la igualdad efectiva de mujeres y hombres y el Plan Estratégico de Igualdad de Oportunidades 2008-2011, la Secretaría General de Instituciones Penitenciarias aprueba, en noviembre de 2008, el Programa de Acciones de Igualdad entre Mujeres y Hombres en el Ámbito Penitenciario. El programa incluía más de 120 acciones concretas con un doble objetivo declarado: por un lado, atajar aquellas situaciones y circunstancias que perpetuaban un trato discriminatorio de las mujeres en la ejecución penitenciaria y, por otro, aprovechar activamente el tiempo de permanencia en prisión para contribuir a romper las barreras sociales y personales de las mujeres que pudieran dificultar una adecuada inserción social y el pleno ejercicio de sus derechos de ciudadanía (Yagüe, 2012: 49). Del conjunto de medidas recogidas en ese programa, se destaca la propuesta de priorización y generalización de los $\mathrm{MdR}$ procurando que se apliquen con el mismo nivel de calidad a los centros y a los departamentos de mujeres. Como resultado de esta propuesta, los $\mathrm{MdR}$ experimentan una expansión sin precedentes en las prisiones femeninas. De hecho, en un determinado momento, se establece que todos los centros con presencia de mujeres deben tener un $\mathrm{MdR}$, lo que, unido al hecho de que ellas tradicionalmente han ocupado un único módulo de las prisiones (con la excepción de las cárceles solo de mujeres, de las que solo hay tres en el Estado español - Alcalá de Guadaira en Sevilla; Brieva en Ávila y Alcalá de Henares, Madrid² y algunas otras en las que hay dos módulos, como Estremera en Madrid o Mansilla de las Mulas en León-, en este último caso, uno de los módulos es de carácter mixto), se traduce en que la gran mayoría de las presas van a pasar a cumplir condena bajo esta modalidad de régimen, al menos en teoría. Los análisis posteriores de la implantación de este programa penitenciario en el caso femenino han puesto de manifiesto que su puesta en marcha se ha desarrollado bajo un sistema de expansión incompleto. De esta forma, dado que las mujeres se encuentran concentradas normalmente en uno de los módulos de la prisión, su conversión en un MdR provoca que se vean obligadas a incorporarse a este programa, aunque en teoría tenga un carácter voluntario. En el caso de negarse o de ser expulsadas, son trasladadas a otros centros penitenciarios, con los perjuicios que ello provoca para sus relaciones sociales, el entorno, los vínculos sociales y familiares. Otra opción que se ha tomado en algunos centros es la convivencia de ambos modelos (el sistema de cumplimiento en régimen ordinario y en régimen de $\mathrm{MdR}$ ) en el mismo espacio físico. Una de las plantas la ocupan aquellas que han decidido incorporarse al sistema de los MdR y la otra planta es ocupada por aquellas que han decidido mantenerse en el régimen ordinario, aunque en el resto del módulo los espacios y las dinámicas continúan siendo compartidas. Esto hace que, a las mujeres, les

2. Cataluña tiene transferidas las competencias en materia penitenciaria, por lo que este análisis solo se aplica a aquellas prisiones que se encuentran bajo la responsabilidad de la Administración General del Estado. 
vuelvan a faltar unas condiciones igualitarias en el disfrute de los programas y las condiciones de aplicación, a pesar de que inicialmente era el objetivo perseguido con la incorporación de esta medida al programa (Ballesteros y Almeda, 2015).

El presente artículo pretende ofrecer un análisis de los MdR de mujeres, en el contexto de las principales líneas de estudio del encarcelamiento femenino en el Estado español, desde un enfoque crítico feminista ${ }^{3}$ y en el marco de ciertas aportaciones desde la criminología feminista a nivel internacional. Desde estos enfoques, el género se concibe como un principio articulador de las formas institucionales de control social y castigo, de cuya aplicación se derivan conocimientos científicos que pueden ayudar a desarrollar políticas públicas que contribuyan a establecer una mayor justicia social y a construir sociedades más igualitarias, pero partiendo del hecho de que no existe una única perspectiva feminista, sino una diversidad de las mismas (Gelsthorpe, 2002; Heidensohn y Gelsthorpe, 2007; Chesney-Lind y Morash, 2013; Renzetti, 2013). Con este artículo, se busca realizar una aportación en el estudio de las formas que adopta el castigo de las mujeres en los inicios del siglo XXI en el Estado español, ofreciendo un primer abordaje de las continuidades y discontinuidades que se identifican en el análisis de la evolución de las pautas de la ejecución penal femenina. Se enmarca, por tanto, en una línea de estudio que se plantea articular los análisis tradicionales, aunque todavía vigentes, de las disciplinas penales dirigidas a las mujeres encarceladas, con las más recientes aportaciones en el abordaje de las estrategias neoliberales del gobierno de la penalidad (Garland, 1996, 2001), para identificar las mutaciones de los sistemas penales y contribuir a mejorar nuestra comprensión de las interrelaciones e interdependencias de varias estrategias y lógicas de castigo (Hannah-Moffat, 2001: 163).

En el marco de esta línea de estudio, en este primer artículo se buscará profundizar en el eje de las continuidades en el modelo de ejecución penal femenina en el Estado español, abordando sus formas específicas y las variaciones que sufre en la actualidad, enlazando con las aportaciones realizadas en el abordaje sociohistórico del castigo femenino desde el Antiguo Régimen (Almeda, 2002; Hernández, 2013). A esto se añadirán también algunos apuntes que nos permiten vislumbrar ya ciertas conexiones con los nuevos rasgos emergidos en el marco de las formas de gobierno de la penalidad contemporánea. A este primer eje, que centrará el presente artículo, se le ha denominado la estrategia de la redomesticidad de las mujeres encarceladas (Ballesteros, 2014; Ballesteros y Almeda, 2015). El segundo eje de análisis, que será abordado en un segundo artículo actualmente en elaboración, estará orientado al abordaje de las discontinuidades y mutaciones en el modelo de ejecución penal femenina,

3. En el Estado español, los indicios apuntan a que no podríamos estar hablando propiamente de una criminología feminista, sino de un conjunto de estudios que, desde los años noventa, han ido abordando temas vinculados al sistema de justicia criminal desde una perspectiva de género. En los últimos años, se ha producido una proliferación de dichos estudios que podrían sentar las bases para la futura consolidación de este subcampo. 
impulsadas en el marco del neoliberalismo penal, que, en interacción con las continuidades anteriormente apuntadas, tienen como resultado el conjunto de condiciones en las que se da la privación de libertad femenina en las cárceles de la actualidad. A este segundo eje, que enlaza con otras aportaciones ofrecidas en el contexto internacional (Hannah-Moffat, 2001; Bosworth, 2007), se le ha denominado, siguiendo a Garland (1996), la estrategia de la responsabilización (Hannah-Moffat, 2001).

\section{Metodología}

Este artículo se enmarca en el proyecto de investigación en curso que constituye la tesis doctoral de la autora, en el que se pretende estudiar las formas que adopta el encarcelamiento femenino en el Estado español en el siglo XXI, en el marco del análisis de las políticas de igualdad y tomando como estudio de caso los MdR. El trabajo de campo para el presente artículo ha consistido en un estudio de caso etnográfico en MdR con presencia de mujeres en el sistema penitenciario español, desarrollado entre los meses de noviembre de 2013 y septiembre de 2014. El trabajo de campo cualitativo consistió en la realización de visitas y entrevistas en tres centros penitenciarios:

- Un centro exclusivo de mujeres en el que, a día de hoy, existen seis módulos, tres de los cuales se configuran en MdR: dos de nivel 3 o máxima exigencia y uno de exigencia básica o nivel 1 (según denominación de la circular 2011 citada más arriba).

- Un centro penitenciario en el que actualmente hay un único módulo de mujeres, en teoría calificado como de máxima exigencia (nivel 3), y que constituye uno de los ejemplos de aplicación combinada de los principios de los MdR y de los módulos ordinarios en un mismo espacio físico, que se mencionaba anteriormente. La observación cotidiana del funcionamiento del módulo y las entrevistas realizadas han permitido constatar cómo prácticamente ninguno de los rasgos característicos de los MdR se daba en el régimen de vida de las mujeres en esta prisión.

- Por último, un centro penitenciario en el que existen dos módulos con presencia de mujeres: uno de ellos de régimen ordinario y el otro de respeto, con la particularidad de que este último módulo es de carácter mixto y en él conviven hombres y mujeres en igual número.

El trabajo de campo llevado a cabo en cada uno de los módulos consistió en la realización de entrevistas, observación directa no participante y asistencia a algunos eventos organizados en los centros penitenciarios. Asimismo, para completar el estudio de los MdR, se realizaron varias entrevistas a responsables y exresponsables de instituciones penitenciarias en el periodo 2004-2011 y 2012 en adelante. En total, se llevaron a cabo alrededor de 86 entrevistas a mujeres de los diferentes módulos, así como a aproximadamente 23 miembros de los equipos técnicos y profesionales de los centros. 
La presencia periódica y continuada de la investigadora en dos de los centros ${ }^{4}$ ha favorecido la generación de contactos y conversaciones informales que exceden de lo que se ha podido recoger en las grabaciones y transcripciones del diario de campo. Respecto a las tareas metodológicas, todas las entrevistas fueron transcritas y posteriormente analizadas con el software de análisis cualitativo Atlas.ti.

\section{Disciplina, domesticidad y moralización: \\ Las claves del encarcelamiento femenino a lo largo de la historia}

Los centros de reclusión de mujeres en España, en el marco de un sistema heteropatriarcal, han estado marcados, desde sus orígenes, por la aplicación de un régimen de vida caracterizado por la fuerte disciplina, la domesticidad y la moralización (Almeda, 2002), con el objetivo de castigar a las mujeres por su doble transgresión: no solo de la ley penal (desviación delictiva), sino también de las normas que han regulado la condición femenina (desviación social) (Almeda, 2002).

Como ya ha sido acertadamente apuntado por Almeda (2002, 2003), a partir de su estudio del caso español, y Bosworth (2000), para el francés, la explicación foucaultiana (1975) del cambio en las formas de castigo a partir del siglo XVIII, caracterizada por el paso del castigo físico y corporal a una vigilancia disciplinaria, resulta insuficiente para explicar el castigo en el caso de las mujeres, teniendo en cuenta que, para ellas, la privación de libertad había sido una constante durante el antiguo régimen, y la forma que este castigo adoptaba, con la disciplina y el control como sus ejes esenciales, no había supuesto grandes novedades. Similar crítica tiene como foco la explicación desde el enfoque económico-estructural (Melossi y Pavarini, 1987), en la que se enfatiza la conexión íntima entre el surgimiento del modelo de producción capitalista y el nacimiento de la prisión, y en el que, de nuevo, se obvia cualquier referencia a las condiciones del encarcelamiento femenino (Almeda, 2002).

En el Estado español, el proceso de modernización que conllevó la paulatina puesta en marcha de sucesivas reformas a partir de las que se consagraría la privación de libertad con características más o menos rehabilitadoras o resocializadoras, siguiendo la terminología oficial (Hernández, 2013), prácticamente no supondría cambios en el encarcelamiento femenino hasta las últimas décadas del siglo xx, y aún así de forma deficiente, como luego se verá (Almeda, 2002; Hernández, 2013). Quedaría, por tanto, el encarcelamiento femenino históricamente configurado a partir de la concurrencia de tres rasgos esenciales:

- En primer lugar, la disciplina, entendida como la imposición de unas férreas rutinas de actividad y control de conductas que serán minuciosamente vigiladas por las autoridades, tradicionalmente vinculadas con la Iglesia católica. En definitiva, una vigilancia del alma y del cuerpo, olvidada

4. En el caso de la tercera de las cárceles estudiadas, se realizaron dos visitas de varios días en los meses de noviembre de 2013 y mayo de 2014. 
en las explicaciones sobre la génesis de la prisión, pero que tan presente ha estado en el castigo de las mujeres.

- En segundo lugar, la moralización, asociada claramente a la conexión entre delito y pecado, tanto en su vertiente religiosa como en la vinculada con la moral sociosexual dominante (Hernández, 2013: 149). En este sentido, la presencia de órdenes religiosas en las prisiones de mujeres ha sido prácticamente una constante en toda la historia del encarcelamiento femenino, lo que tiene reminiscencias incluso en la actualidad, con el peso de asociaciones con raíces o vinculaciones eclesiales. Los rezos continuos, la presencia de imágenes religiosas y el discurso moralizador han persistido durante siglos.

- Por último, la consagración del modelo de domesticidad a partir de la modernidad, con la delimitación de las esferas de actuación asociadas a cada uno de los géneros: lo público, como el ámbito del trabajo remunerado, y lo privado, donde se ubica la familia y el hogar. Este discurso de la domesticidad ejercerá una gran influencia en el siglo XIX español a partir de su materialización en la figura del «ángel del hogar», perfecta madre y esposa (Nash, 2004: 40), y se convierte también en la representación femenina ideal a la que las mujeres encarceladas tienen que parecerse. A ello contribuirán, además, los mecanismos de control formal e informal que operarán tanto dentro como fuera de las cárceles (Miralles, 1983; Hernández, 2013: 151).

Durante el breve periodo en el que Victoria Kent ejerció como directora general de prisiones, se produjeron pequeñas modificaciones en este modelo de castigo femenino imperante. Su mandato fue marcado por la humanización y la mejora de las cárceles femeninas, a pesar de que su política penitenciaria continuaría marcada por tintes sexistas (Almeda, 2002: 119). A partir de la Guerra Civil y durante las casi cuatro décadas de dictadura franquista, los tres grandes rasgos arriba apuntados se agudizarían de forma evidente, a lo que se añadiría la redención de las penas por trabajo como instrumento de sumisión dentro de las cárceles. Este se configuraba como un sistema premial-punitivo que contribuía a asegurar solamente la liberación de los más dóciles (Hernández, 2013: 173-174). Las mujeres participaron de este discurso de la redención, ajustado a las labores consideradas propias de su sexo, aunque en mucha menor medida que los hombres (Mapelli, Herrera y Sordi, 2013: 64), con lo que se alimentaba el discurso de la domesticidad, a lo que contribuían también otras actividades como las denominadas «escuelas de hogar», patrocinadas por la Sección Femenina en algunas cárceles (Hernández, 2013: 174). Por último, junto a las actividades de costura «oficial», las presas desarrollaron ampliamente trabajos informales de confección que se vendían en el exterior y que contribuían a su propio mantenimiento y el de su familia (Hernández, 2013: 175).

En su estudio del encarcelamiento femenino en el Estado español en la etapa democrática, Almeda (2002, 2003), con ecos claros de investigaciones desarrolladas en otros países europeos, pone de manifiesto que las condiciones de cumplimiento de la pena privativa de libertad en el caso de las mujeres mantienen una serie de continuidades que anclan sus raíces en las primeras 
instituciones de reclusión femenina. El peso de la moralización, ejemplifica$\mathrm{da}$, entre otros elementos, por la persistencia de la presencia de asociaciones vinculadas con la Iglesia católica; la continuidad de actividades que refuerzan la lógica de la domesticidad (aspecto también recogido por autoras en el contexto internacional, entre otras: Giallombardo, 1974; Smart, 1976; Carlen, 1985; Heidensohn, 1985; Dobash, Dobash y Gutteridge, 1986; Bertrand et al., 1998; Campelli et al., 1992, etc.), así como un régimen disciplinario y de control mucho más duro y rígido que el que se aplica en las cárceles de hombres (Carlen y Worrall, 2004: 9), adoptando formas como la medicalización (Almeda, 2002; Carlen y Worral, 2004), constituyen una buena muestra de esas continuidades que se indicaban.

El peso de la división entre público y privado, clave en la idea de domesticidad, ha sido también utilizado, con lecturas matizadas, por otras criminólogas feministas en su estudio de las mujeres presas. Así, Bosworth (1999) considera esta división como un elemento crucial en la comprensión del encarcelamiento, por cuanto la distinción entre ambas esferas sufre una cierta inversión en el horizonte carcelario cuando determinadas actividades relegadas al ámbito privado pasan a ser realizadas en público. Este proceso de intromisión con frecuencia impacta más duramente en las mujeres, no solo porque determinadas prácticas como los cacheos por drogas son más intrusivas para ellas, sino también porque estas adquieren diferentes significados, ya que muchas mujeres encarceladas han sufrido abusos sexuales. Así, en este proceso de desplazamiento de aspectos privados al terreno público, la institución usa los ideales de feminidad para controlar la actividad de las mujeres (Bosworth, 1999: 110). Ahora bien, la autora también plantea cómo el proceso de expansión del espacio en el que las necesidades femeninas son discutidas y examinadas puede contribuir, a su vez, al propio empoderamiento de las mujeres (Bosworth, 1999: 111). Ello posibilita el desarrollo de mecanismos de resistencia de las presas frente a su propio encarcelamiento, así como frente al control y a la disciplina ejercidos sobre ellas por la propia institución. Partiendo de la concepción del poder como algo relacional y no absoluto —enfoque ampliamente popularizado desde determinadas corrientes feministas-, algunos análisis criminológicos consideran que el concepto de resistencia puede resultar útil en la comprensión del encarcelamiento, ya que trata de subrayar las luchas de las personas presas para mantener un cierto sentido de autonomía y capacidad de elección en un espacio caracterizado por la ausencia de poder (Bosworth y Carrabine, 2001).

\section{La estrategia de la redomesticidad en los MdR de mujeres}

A lo largo de las siguientes páginas, se van a desgranar determinadas rutinas cotidianas y prácticas de los MdR de mujeres, cuyo análisis pretende demostrar la pervivencia reforzada de un modelo de domesticidad que, a partir de su plasmación concreta en una normativa detallada y respaldada por la firma de un contrato, conduce a una mayor dureza del encierro femenino, sobre la base de un refuerzo de un conjunto de rasgos históricamente persistentes. 
Esta estrategia de la redomesticidad comienza con la omnipresencia de la limpieza, que abarca tanto los espacios privados de la celda como la propia higiene personal, así como las zonas comunes del módulo. Como se ha comentado en la descripción de los MdR, en este modelo, se sustituyen los tradicionales «destinos» (por otro lado, con carácter remunerado) por la asignación a grupos de internas de la responsabilidad de la limpieza y el mantenimiento de las diferentes zonas. Este énfasis en las tareas de limpieza ha sido puesto de manifiesto en el informe de la visita realizada por el Comité Europeo para la Prevención de la Tortura y de todos los tratos inhumanos y degradantes (CPT) realizada en el año 2011, en la que, junto a cierta sensación de un ambiente más relajado en estos módulos, se apunta: «Sin embargo, parece que se daba una importancia desmesurada a las tareas de limpieza y los reclusos con los que se entrevistó la delegación afirmaron que no se atrevían a quejarse sobre las condiciones de vida en el módulo por miedo a ser sacados de él» (CPT, 2013: 33). Las pequeñas deficiencias que se pueden identificar en el desarrollo de estas tareas, que, no obstante, al ser valoradas por los profesionales y las profesionales de vigilancia, pueden gozar de una dosis más o menos elevada de arbitrariedad, serán calificadas con un negativo, puntuación de la que se derivarán consecuencias, tanto a la hora del reparto grupal de trabajos como para la propia presencia en el MdR de la persona interna. La acumulación de negativos en un periodo determinado conlleva la expulsión del módulo, temporal o permanente, con lo que el miedo a salir de este sistema y perder los «beneficios» que implica es identificado como una fuente de estrés para las mujeres presas.

Ya sabemos las guardias que suben a hacer revisiones en las celdas y las que no. Pero, aún así, uno no se relaja, uno siempre está en alerta y, con el paso de los días, saber ya cómo le gusta y dejar las cosas bien y ya es todos los días como cuando uno va a ser militar, siempre va a hacer la misma fila, y todos los días lo mismo, lo mismo. Yo, por ejemplo, hace más de un año que no cojo negativo. Parece que lo he hecho bien. ¿Sabes? El esfuerzo diario y la costumbre. (Interna 22, MdR CP3)

Ahora bien, en el marco del modelo de domesticidad imperante, tanto la socialización tradicional de las mujeres fuera del espacio de la prisión como el mantenimiento de ciertas inercias de las rutinas carcelarias en el caso femenino, ya recogían el énfasis en las tareas de limpieza y el mantenimiento de las internas dentro de los límites normativos asociados a los modelos de feminidad heteropatriarcales. Los propios profesionales de la prisión constatan que esta área específica no es especialmente problemática en el caso de las mujeres, puesto que, por sí mismas, ya tienden a mantener unos niveles de limpieza y cuidado mucho más elevados que en el caso de los varones. Lo que se produce en el caso de los MdR es, por consiguiente, un incremento exponencial del control y la vigilancia sobre las más mínimas actividades asociadas a la limpieza. Esto es, ya no vale con que esté limpio, en términos generales, sino que tendrá que estarlo de acuerdo con un estándar determinado: las cortinas tienen que 
colocarse de una cierta manera, aunque el baño esté limpio no puede haber una gota en el lavabo, ni una arruga en la cama, con el riesgo de ganarse un negativo, mecanismo sancionador por excelencia que promueve una profundización en la falta de poder y de capacidad de toma de decisiones, incluso en los pequeños comportamientos.

En mujeres, vamos a ver, la mujer es mucho más fácil, por su propio carácter, que acepte las normas de un MdR. Es más ordenada, siempre ¿̇eh?, en cualquier prisión, es más limpia, las tareas de limpieza, de recoger, la salen innatas. A un hombre del (módulo) 14, lo tienes que empujar. Es que no ve el yogur tirado, lo pisa, pero no lo ve. Entonces, el primer paso, la limpieza y el orden, las mujeres ya lo tenían. El segundo paso que es la actividad, muchas lo demandan porque se aburren, entonces ya lo tenían. El tercer paso, más comprometido, que es el control social y de grupo, pues es que también lo tienen. Es que también lo tienen, porque la mujer habla mucho más, se expresa mucho más, cuenta mucho más y, a través de la palabra, también manipula mucho más. No era muy difícil adaptar este sistema a módulos de mujeres. (Educador, CP3)

El trabajo y el desarrollo de actividades orientadas a la formación, al ocio, a la cultura y/o al deporte se refuerzan también en el nuevo sistema. Cada interna tiene la obligación de participar en un número de actividades a lo largo del día y la oferta se extiende también, aunque con menor intensidad, a los fines de semana. El trabajo suele ser, sin lugar a dudas, la actividad más demandada, por cuanto muchas de las personas presas no reciben recursos monetarios del exterior, ya que padecen situaciones socioeconómicas muy precarias (Ballesteros y Almeda, 2015), y bastantes de ellas son, desde dentro, sustento de sus familiares. En este sentido, aunque la prisión provee de kits básicos de higiene personal, su contenido no suele alcanzar a cubrir las necesidades esenciales de las mujeres, que, asimismo, necesitan de recursos económicos adicionales para comprar tarjetas de teléfono, productos de primera necesidad, etc. En estas condiciones, aquellas que cuentan con esa posibilidad se definen, en ocasiones, como "privilegiadas» en el horizonte carcelario, aunque la remuneración sea limitada.

Sí, me ha costado, pero más bien por mi culpa, porque antes yo era, no digamos rebelde, pero era de las que a la mínima saltaba, entonces aquí los trabajos tienes que tener un poco de..., tragarte algunas cosas, morderte la lengua y saber... Y sí, me ha costado, pero también mi condena es muy larga y yo a los dos años tampoco podía..., que me dieran un trabajo. Me lo han dado ahora y lo voy a mantener, porque lo necesito y me ha costado mucho, la verdad que sí. (Interna 5, MdR CP3)

No obstante, la oferta laboral de la prisión todavía continúa reforzando el discurso de la domesticidad, por lo que mantiene ciertas actitudes estereotipadas sobre los empleos más adecuados para las mujeres o los varones. En una de las cárceles estudiadas, por ejemplo, se desarrollaban talleres productivos de diversa naturaleza, muchos de los cuales fueron cerrados en el contexto de la 
crisis económica de los últimos años y a los que las mujeres tenían prohibido el acceso. Por otro lado, muchas veces, la mujer presa debe realizar de manera previa un trabajo voluntario que vaya generando una imagen determinada en la institución sobre su buena disposición y que sirva como transición hacia un posible futuro trabajo remunerado.

Respecto a la oferta de actividades en los MdR, estas se han multiplicado de forma exponencial, tanto las ofrecidas por la propia institución como aquellas diseñadas y gestionadas por las propias mujeres, práctica esta que enlazará en futuros trabajos con el análisis de la denominada «estrategia de la responsabilización» (Garland, 1996; Hannah-Moffat, 2001). Además de las actividades de educación reglada, también se desarrollan algunos talleres productivos, que se supone buscan la capacitación de las personas en el contexto del ideal de reeducación y resocialización incluido en la normativa penitenciaria. Ahora bien, estas actividades no son ni mucho menos las más numerosas. Lo que prolifera en los MdR es un conjunto de actividades deportivas de toda índole, idiomas, manualidades, yoga, marquetería, entre otras, que buscan dar respuesta a esa exigencia de realización constante y obligatoria de actividades que se da en el marco de los MdR. A partir de una selección inicial de las actividades en las que la persona interna quiere participar, la asistencia es obligatoria, so pena de recibir un negativo o una puntuación desfavorable si finalmente no se acude a las mismas. Por tanto, la concepción sobre el marco de posibilidad de elección viene de nuevo determinada por lo que la institución considera, y el margen de autonomía tiende a limitarse en este punto (Hannah-Moffat, 2001: 173).

Tú te apuntas a las actividades: a punto de cruz, a biblioteca, a gimnasio o escuela. Y si tú dices, pues por las mañanas a escuela, todas las mañanas tienes que estar en la escuela, «obligá». Y todas las tardes..., eso a primera hora, de 9.30 a 11, a las 11 a 11.30 tienes un descanso. A las 11.30, vas a hacer la segunda actividad hasta las 12.15 o 12.30 , según, y ahora por ejemplo tienes que estar en punto de cruz y si ese día no me apetece coser, «quiero de ir» al gimnasio porque tienes gimnasio dentro del módulo, no puedes. En Córdoba obligado. Tienes que estar los 7 días, la actividad que tú hayas elegido de lunes a viernes o yo quiero estar nada más cosiendo lunes, martes y miércoles, obligado. En Granada no, en Granada yo estaba mejor, porque me cogía, «ay, me voy a poner hoy a marquetería» y me ponía a hacer mi cuadro. Luego la segunda hora no quería estar en marquetería, me voy para coser o a lo mejor, pues no era obligado estar en esa actividad, en Córdoba, sí. (Interna 4, CP2)

Por el contrario, en los módulos ordinarios, la incorporación al denominado "tratamiento», que no es más que un plan de actividades y/o trabajos al que se decide acceder o no, tiene un carácter voluntario, aunque esto cambia la imagen que la institución tiene respecto a la voluntad de rehabilitación y puede comportar consecuencias en la toma de decisiones de la junta de tratamiento a la hora de conceder permisos u otros beneficios. Un efecto de la implantación de los MdR ha sido también la limitación de las actividades en los módulos 
ordinarios, con el fin de marcar las diferencias y las ventajas asociadas al nuevo modelo de respeto y "forzar» a las personas internas a asumir las normas asociadas a este, a cambio de disponer de más opciones para cubrir el tiempo de encarcelamiento (Ballesteros y Almeda, 2015).

Aquí trabajas, tienes actividades, jolín, que puedes hacer cosas. En el otro módulo, no; en el otro módulo, es como el ganado. Tú abres una cuadrina, metes cuatro ovejas, cierras y ahí las dejas siempre. Pues es lo mismo. Solo que aquí, aunque seamos ganado, tenemos la ventaja de que podemos salir a pastar. Ni más ni menos. (Interna 13, MdR CP3)

Por tanto, el énfasis en la limpieza, y sobre todo la forma en la que esta se planifica y se estructura meticulosamente en el marco de los MdR, unido al esquema de «inactividad 0» que impera en la programación diaria y obligatoria de actividades y trabajos, supone un claro refuerzo de la vigilancia y del control férreo que ha estado siempre presente en el encarcelamiento femenino. A esto se unen determinados mecanismos que tienen ciertas reminiscencias con la práctica de la redención de la pena por trabajo instaurada durante el franquismo (Hernández, 2013: 172-176). En este sentido, en algunos casos, se ha hecho efectiva una de las posibilidades del reglamento penitenciario a partir de la cual se puede conseguir el adelanto del tercer grado con la incorporación a los MdR. Esto es, por cada año en un MdR, se reduce en unos meses el tiempo que la persona debe estar cumpliendo condena encerrada en prisión. Las posibles expulsiones temporales o permanentes del módulo pueden modificar este calendario, de forma tal que de nuevo el poder de la institución marca los contornos y altera los tiempos de castigo, en función de la conformación o no a las normas que esta impone.

Conformación a las normas que, como ya antes se apuntaba, debe realizarse siguiendo unos límites claramente definidos. En este sentido, la institución busca uniformizar las conductas de las presas mediante ideales determinados de respetabilidad o a través de un modelo concreto del buen hacer. Así, determinadas prácticas que suponían el mantenimiento de cierta autonomía e identidad personal por parte de las mujeres encarceladas — por ejemplo: la forma en que se disponían los enseres en las celdas o la decoración de las mismas- son objeto de intervención o sanción si no responden a los modelos normalizados de la institución carcelaria.

Fui con unos periodistas a visitar el módulo y aquello era una selva. Una selva [en la] que las celdas estaban muy bien, muy bonitas, pero con cortinas, con 20 pares de zapatos, un montón de vestidos, aquello era alucinante. Había que cortar por algún lado. Eso también estaba así porque no se había puesto orden por parte de las funcionarias y no había..., como norma general, no había la dejadez y la desidia que puede haber en algunas celdas de internos. Al revés, pero era por el otro lado, era excesivo, pero tenían que aprender a controlarse, a tener lo necesario, a limpiar como tienen que limpiar, a organizarse, a planificar el tiempo. Todo eso exactamente en hombres que en mujeres. También 
en los departamentos de mujeres, también hay gente que..., hay kíes ${ }^{5}$ o gente que impone y demás. (Exmiembro del equipo directivo, CP3)

Ahora bien, como se recogía en apartados precedentes, la estrategia de desempoderamiento no resulta siempre exitosa por parte de la institución y, a pesar de los intentos evidentes de las autoridades, de forma más o menos explícita, las mujeres van a tratar de desarrollar prácticas que les permitan mantener ciertas cotas de poder y autonomía, y que en muchas ocasiones desafían las limitaciones que implica la prisión. Frecuentemente, estas prácticas están asociadas al uso y a la resignificación de aquellos atributos asignados a la domesticidad y al modelo de feminidad que la institución impulsa. Un ejemplo de ello son los trabajos informales que todavía muchas mujeres realizan en los $\mathrm{MdR}$, a pesar de que esta práctica está prohibida y sancionada por la institución. Sin embargo, desafiando la normativa, y aunque ellas han aceptado las normas del MdR, prácticas como la realización de la colada a otras internas, peluquería, manicura, realizar manualidades y objetos de costura de diverso tipo siguen siendo llevadas a cabo por las mujeres que, muchas veces gracias a ello, consiguen obtener unos recursos económicos básicos para comprar tarjetas telefónicas o algunos productos de primera necesidad. Otras actitudes de solidaridad económica informal entre las presas — por ejemplo: adquirir productos u objetos básicos para otras, como un café o un refresco-, y que están prohibidas también desde la institución, constituyen pequeñas estrategias de resistencia de las mujeres presas.

Creo que por eso le caigo mal a muchas, porque cuando fui la presidenta, lo dije desde un comienzo: somos compañeras y debemos de cubrirnos las espaldas unas a otras. Los funcionarios son nuestros jefes inmediatos, nuestros superiores inmediatos a quien hay que respetar, pero las que tenemos que cuidarnos somos nosotras entre sí, y no me gustan los chivateos. Y lo dije desde un comienzo, odio, u odiaría enterarme que una de ustedes se ha quejado contra otra de nosotras, la que sea. Aquí hay personas que tienen diferentes formas de ganarse la vida. No está permitido, ellos consideran un trapicheo que yo compre un paquete de tabaco para otra persona, porque puede estar pagándole por un móvil, o puede estar pagándole por droga o puede estar pagándole por cualquier otra cosa, pero hay personas que lavan porque no tienen quien les ponga peculio. No es mi caso, yo, a Dios gracias, tengo mi madre, mi abuela y mis hermanos allá fuera que están aquí, y cuando no puedo por lo que sea ellos responden por mí. Pero hay personas que están solas y tienen que lavar a muchas internas para ganarse un paquete de Marlboro a la semana y eso aquí no está permitido. $\mathrm{O}$ tal vez tienen que coser, o tal vez tienen que comprarse tela con lo que lavan para hacerse los cojines que hacemos aquí, que no sé si los has visto, ya te mostraré luego uno, y así se ganan la vida. Y eso aquí no está permitido, no se puede decir yo le pago a fulana porque no, no se puede. (Interna 6, MdR1, CP1)

5. En el argot carcelario, se refiere a aquellos presos con una amplia trayectoria carcelaria que ejercen su poder mediante coacciones sobre otras personas presas. 
El refuerzo del modelo de la domesticidad en los MdR no se agota con lo indicado hasta el momento. El ideal de la feminidad asociado a la dependencia y a la sumisión de las mujeres que son consideradas menores de edad y con limitada capacidad autónoma para la toma de decisiones es reforzada por la institución mediante estrategias infantilizadoras y de búsqueda de la obediencia a partir de la amenaza de expulsión del módulo, lo que se refuerza también con la promoción de imágenes estereotipadas sobre el perfil de las mujeres que se encuentran en los módulos ordinarios, "esas otras conflictivas» que no aceptan las ventajas que supone la presencia en los MdR. En esta línea, uno de los paralelismos más comúnmente expresados por las internas es el que se da entre estar en un MdR y en un colegio o en un internado. El control minucioso de las actividades cotidianas, la programación detallada de tareas, la obligación de mantener los espacios limpios y ordenados de acuerdo con unos estándares exigentes y definidos por la institución, la corrección de las conductas, por más minúsculas que parezcan, o la necesidad de pedir permiso para cualquier acción que se quiera desarrollar entran dentro de esta estrategia de infantilización. No en vano, las mujeres expresan que hay determinadas intromisiones u órdenes que están fuera de lo que ellas consideran la actitud con la que se debe tratar a una persona adulta que cuenta con un bagaje existencial y responsabilidades personales, laborales y familiares diversas.

Son muchas normas: a tal hora te duchas, a tal hora haces esto, a tal hora haces lo otro, a las 11 apagas la tele. Es que son cosas muy... Que ni tú teniendo hijos les pones tantas normas. Yo se lo he dicho muchas veces al educador. A mí es que, sinceramente, ni en un colegio de niños lo he visto tan así. Y los castigos van así y las venganzas van así. (Interna 3, MdR CP3)

La amenaza de expulsión del módulo por la acumulación de valoraciones negativas y las consecuencias que de ello se derivan, respecto a ciertas ventajas en el acceso a actividades, empleos remunerados o en la opinión que la institución tenga, sobrevuela la vida cotidiana en los MdR. Las puntuaciones negativas, las órdenes del personal, etc. no pueden ser discutidas, salvo que se asuma el riesgo de recibir un nuevo negativo o incluso un desfavorable. Por ello, ante ciertas arbitrariedades o actuaciones consideradas injustas, la máxima es callar y aguantar. Esta postura de sumisión es asumida con una actitud más o menos resistente por parte de las mujeres, de modo que, en muchos casos, estas son claramente críticas ante las sanciones que la institución les impone y consideran determinadas normas como arbitrarias y más condicionadas por «la guardia que toque» que por su conexión con una determinada forma de tratamiento o actuación. Asumen de manera abierta esas normas y consideran que dicha forma de proceder no va a cambiarlas ni a resocializarlas. Ellas no se identifican con una imagen de delincuentes o desviadas, sino que, muy al contrario, se consideran personas normalizadas, respetuosas, responsables y autónomas. Por otro lado, en línea con las resistencias arriba indicadas, muchas de ellas deciden adoptar ese perfil de "buena presa» para poder mantenerse y obtener los beneficios derivados de su presencia en el módulo, pero transgreden conscientemente determinadas normas, como la prohibición del uso de 
teléfonos móviles, o asumen los riesgos asociados a ciertas conductas, como estar acostada en horas prohibidas, entre otras.

Entonces tú estás actuando con un interno y te va a dar la apariencia que necesita y que le viene bien para conseguir lo que quiere como hace cualquiera en su vida particular, y en el módulo de respeto más. Seguro que hay muchas internas que parece que aceptan las normas de buen grado y que está todo muy bien, y por detrás a algunas de ellas no les gusta que les prohibamos determinadas cosas o que no les gusta que les obliguemos a realizar determinadas actividades. (Equipo directivo, CP1)

No obstante, a pesar de estas pequeñas resistencias cotidianas, la institución despliega mecanismos más amplios y sutiles para ejercer su control. Dentro de un espacio de control formal, como es la prisión, el poder punitivo opera mediante mecanismos de control informal, como es el recurso a la familia (Miralles, 1983), para afianzar la vigilancia sobre los comportamientos de las mujeres presas. Un ejemplo de este control informal es el que se despliega a través de ciertas actividades como las jornadas de convivencia, en las que las mujeres reciben las visitas de sus parientes. En ellas, el equipo directivo y técnico da la bienvenida a las familias, explica qué son y cómo funcionan los MdR; a continuación, las mujeres ofrecen un pequeño festival con actuaciones musicales y de diversa naturaleza, para finalizar con una visita a las diferentes áreas del centro penitenciario y una pequeña merienda en los módulos, con la posibilidad de acceder a las celdas y de compartir un tiempo con sus seres queridos. A la salida, el equipo de la prisión despide a las familias y trata de intercambiar impresiones sobre lo que han observado en la visita y cómo han visto a sus familiares encerradas. Pero lo que puede conceptualizarse como un mecanismo para relajar a los parientes sobre las posibles imágenes estereotipadas que puedan tener del universo carcelario, se convierte también en un mecanismo indirecto de presión sobre las mujeres encarceladas. No en vano se les recuerda que estar en el MdR supone un privilegio para ellas, por cuanto gozan de más beneficios y de una mejor calidad de vida, pero deben mantenerlo mostrando un comportamiento adecuado y una actuación conforme a lo que la institución determina como correcto.

Todos estos mecanismos que la institución penitenciaria despliega en el marco de los MdR no hacen más que continuar el modelo de la domesticidad «revisitada» que cuenta con tantos siglos de vigencia, configurando un sistema reforzado de vigilancia y de control que, sobre la base de las imágenes estereotipadas de las mujeres presas y matizado en función de las variables de nacionalidad, etnia y clase social, perpetúa un tratamiento diferencial y más duro para las mujeres encarceladas.

En la interconexión entre esta perpetuación de las imágenes estereotipadas de las mujeres, tan profundamente enraizadas, y las nuevas estrategias de reconstrucción de subjetividades dicotómicas, polarizadas y ambivalentes que el conocimiento criminológico despliega en la era del gobierno neoliberal, se ubica lo que Garland (1996) ha denominado «criminología del yo» y «crimino- 
logía del otro». Por "criminología del yo», entiende el ejercicio mediante el cual la persona que delinque es caracterizada como un consumidor racional, como podríamos ser cualquiera de nosotras; «la criminología del otro» nos remite, por el contrario, a un amenazante marginado, desconocido temible, a los excluidos, amargados (Garland, 1996: 461). Hannah-Moffat (2001: 166-167), en su análisis del encarcelamiento femenino en Canadá, conecta esta "criminología del yo", que brinda una imagen neoliberal de un individuo responsable y racional, con las imágenes ofrecidas por los grupos feministas, aborígenes o reformistas en relación con las mujeres encarceladas. Este ejercicio de reconceptualización de las subjetividades de las presas opera también en las visiones que el sistema promueve sobre las mujeres sometidas a control penal, que, en muchas ocasiones, tienden a reforzar un perfil de mujeres, equiparables, por un lado, a las que nos podemos encontrar extramuros, pero con un componente reforzado de victimización y totalmente desempoderadas. Esta "criminología del yo» contribuye a enfatizar, en general, las diferencias de perfil entre las mujeres y los hombres presos. Pero, en el marco de los MdR, tiene otras utilidades: por un lado, contribuye a establecer una mejor comprensión de los argumentos aducidos para la generalización de estos módulos en el caso femenino (Yagüe, 2012: 52) y, por otro, contribuye a profundizar, entre las propias encarceladas, las autoridades y otros grupos afines, esa visión dicotómica de las mujeres que están en MdR y de aquellas que están en «módulos conflictivos». Estas últimas son encapsuladas en el perfil de «la otra» conflictiva, disruptiva, en ocasiones violenta, que no es capaz de asumir el respeto que supone la vida en los MdR. En ocasiones, es el propio desconocimiento de la realidad y las características de las personas que están en los módulos ordinarios "conflictivos» lo que contribuye a hacer más profunda esta dicotomía; otras veces es la permeabilidad de ambos sistemas lo que impulsa este ejercicio de diferenciación entre quienes «han cometido un error» $\mathrm{y}$ «aquellas otras delincuentes».

Luego ves, bueno, lo que te decían en ingresos, cuidado porque tú has cometido un error, pero aquí hay delincuentes. Ellos la diferencia que hacen es, cometer un error es la primera vez que haces algo al margen, que no es legal, y en cambio hay gente que lleva viviendo de ello toda la vida, esa es la diferencia y bueno me hizo sentir de alguna forma reconfortada dentro del shock inicial que los educadores me hicieron esa distinción. (Interna 6, MdR2, CP2)

Todo ello aderezado con el peso que variables como la etnia y la nacionalidad tienen en la forma de operar de la "crimonología del yo» y en la «criminología del otro» (o la otra). Por ejemplo: la visión estereotipada que se tiene de las mujeres latinoamericanas que se encuentran encarceladas por tráfico de drogas, cuyos delitos fueron cometidos como resultado de la pobreza en la que vivían, en ocasiones, "víctimas de situaciones de violencia» $\mathrm{y}$ «subyugadas por el machismo imperante en sus sociedades de origen", contrasta a veces con la imagen que se tiene de las mujeres gitanas, que constituyen también una minoría significativa en nuestro sistema penitenciario y que, a partir de la investigación realizada, se encuentran con menos frecuencia en los MdR. 
Por otro lado, y a pesar de esta estrategia sistemática de diferenciación de las "otras», desde esas posiciones marginales, se realizan ejercicios de resistencia tendentes a reconfigurar esa imagen desplegada desde diferentes sectores. Mediante la definición de una identidad no esencialmente distinta de la atribuida a aquellas mujeres presas en MdR o mediante la asunción de prácticas cotidianas que replican las que cotidianamente caracterizan el modelo de domesticidad de los MdR (por ejemplo: la limpieza sistemática de los espacios comunes), se busca contestar esa imagen negativa desplegada por la institución.

¿Aquí sabes lo que dicen los funcionarios cuando sales? «¿De qué módulo eres?». «Del 10», porque tienes que decirlo. Allí en el sociocultural: «iEh! ¿De qué módulo eres?». «Del 10.» «Ah, de las conflictivas.» Un día le dije al funcionario: «Perdone que le diga, pero yo no soy conflictiva, [...] habrá alguna que sea conflictiva, yo no soy conflictiva». Porque yo no me considero de las conflictivas. Aparte que ya te digo que no tengo ningún parte. (Interna 7, Módulo ordinario, CP3)

Por último, y en línea con la argumentación del endurecimiento del régimen penitenciario de las presas en el contexto de la implantación de los MdR, es necesario mencionar el impacto que este nuevo programa ha ejercido en los centros exclusivos de mujeres. Partimos de la asunción de que el encarcelamiento en estos últimos es preferible al encierro en módulos de prisiones de hombres, compartiendo, no obstante, la advertencia de Carlen y Worrall (2004: 59) cuando afirman que las mujeres experimentan faltas de respeto sobredimensionadas, tanto al ser tratadas como si no fueran diferentes a los hombres en prisión, como cuando son consideradas tan diferentes a estos que son los estereotipos paternalistas sobre lo que las mujeres necesitan lo que dicta las propuestas implementadas. El trabajo de investigación desarrollado, tanto en centros exclusivos de mujeres como en módulos femeninos dentro de cárceles de hombres, ha permitido constatar de primera mano cómo los mecanismos de seguridad más evidentes, ciertas dinámicas de movilidad intramodular y en los espacios comunes, así como ciertas normas y prohibiciones, eran de partida menos estrictos, independientemente del tipo de módulo y también de manera previa a la implantación de estos últimos. Con la llegada de los MdR a las prisiones exclusivas de mujeres, fue necesario un endurecimiento de ciertos patrones de comportamiento en el conjunto del centro penitenciario, con el fin de lograr una implementación exitosa de estos, por cuanto en muchos casos ya se gozaba de ciertas ventajas preexistentes (que se habían incorporado como novedad de los MdR) y que, sin embargo, no llevaban aparejadas el plus de control, normas y disciplina que el nuevo sistema consagraba.

Pues en este centro, cuesta mucho sacar adelante un MdR, porque no hay un refuerzo claro entre un $\mathrm{MdR}$ y un módulo ordinario por lo que te digo. Aquí todas salen para todo, con lo cual lo que en otros centros-tipo, de salir a hacer a un área sociocultural una actividad, que si no estás en un MdR no la haces, aquí no existe. Aquí salen todas a todo. Además, todas tienen acceso 
a un puesto remunerado, porque hay muy poquitos conflictos, entonces hay muy poquitas sancionadas. El perfil es bastante colaborador por lo general, es de baja peligrosidad, con lo cual la gran mayoría son muy participativas; a la escuela va un porcentaje muy elevado de internas. Entonces ellas dicen: «Yo soy de Respeto», y la diferencia así que veo es que yo tengo que limpiar igual que limpia el resto, cuando a lo mejor en otro módulo estoy librando. Entonces esa diferencia hace que muchas veces cueste mucho llenar los MdR, por así decirlo, sacarlos adelante. Sí que se han creado ciertos beneficios hacia ellas. (Equipo directivo 2, CP3)

\section{Conclusiones y futuras líneas de investigación}

La tradición de estudios sobre encarcelamiento femenino en el Estado español ha demostrado la existencia de un modelo de castigo basado en el énfasis en la domesticidad, mediante la diferenciación entre el ámbito público y el privado —y el confinamiento de las mujeres en este último—, la disciplina y el control, así como la corrección de conductas y la moralización.

Las dos legislaturas que van desde el año 2004 hasta el 2011, encabezadas por gobiernos de centro-izquierda (PSOE), marcan una serie de cambios en la política penitenciaria caracterizados por un impulso de los programas de tratamiento (fundamentalmente los MdR) y, sobre todo durante la segunda legislatura, el inicio de la atención hacia las mujeres presas mediante políticas de igualdad.

A lo largo de las páginas precedentes, se ha demostrado cómo determinadas características de los MdR, entre las que destacan el énfasis en la limpieza y el mantenimiento del entorno, la pervivencia de tintes sexistas en la oferta laboral, el impulso de una programación diaria minuciosa de actividades y tareas, el control y la vigilancia de las conductas, la corrección de los comportamientos, así como el énfasis en la sumisión y en la dependencia basadas en prácticas infantilizadoras, permiten trazar una línea de continuidad con los rasgos históricamente evidenciados en el encarcelamiento femenino. Ahora bien, en el marco de los $\mathrm{MdR}$, estas pautas tradicionales adquieren, en determinados casos, unos tintes particulares. Mediante la dicotomía que se trata de establecer entre las mujeres que están dentro de los $\mathrm{MdR}$ y las que siguen en los módulos ordinarios, reforzada por la amenaza de la expulsión del MdR, el sistema penitenciario exacerba y redefine el modelo de domesticidad: las prácticas cotidianas y la conformación a las normas deben realizarse siguiendo unos límites definidos y asociados a un modelo concreto de «buen hacer», en el que las conductas son minuciosamente controladas. Se puede hablar, por tanto, de los MdR para mujeres como formas de ejercer una estrategia de la redomesticidad que, configurando un sistema reforzado de vigilancia y control que se asienta sobre imágenes estereotipadas de las presas, y matizado en función de las variables de nacionalidad, etnia y clase social, contribuye a perpetuar un tratamiento diferencial y más duro para ellas. Esto último se muestra, por ejemplo, en las resistencias que han mostrado las propias 
presas de algunos centros exclusivamente femeninos ante la implantación de dichos módulos.

Sin embargo, los estudios sobre prisiones de mujeres han evidenciado también la existencia de ciertas prácticas de resistencia por parte de las mujeres mediante las que estas tratan de mantener ciertas cotas de poder y autonomía, desafiando el control que la propia institución trata de imponer. En el caso de los MdR, el mantenimiento de ciertos trabajos informales o de ciertas acciones de solidaridad económica entre las presas, así como la transmisión de una imagen asociada a una conformación clara a las normas que, no obstante, se combina con la participación en ciertas actividades no permitidas, son algunas de estas prácticas de resistencia.

El estudio de los MdR femeninos ha hecho aparecer también líneas de investigación e hipótesis emergentes en el estudio de las formas que la penalidad contemporánea adopta en el marco del neoliberalismo. Por una parte, convendría profundizar en el análisis de la propuesta de la "criminología del yo" y de la "criminología del otro" (Garland, 1996), con la idea de contribuir a una mejor comprensión del conjunto de las formas de encarcelamiento femenino en la actualidad, en el marco de las mutaciones que se producen en los sistemas penitenciarios contemporáneos en su interacción con las prácticas históricas de castigo. Por otra parte, convendría explorar las consecuencias que la implantación de los MdR tienen en las cárceles masculinas, en la línea de los análisis sobre el control social moderno impulsadas por autoras como Tamar Pitch (2009), quien defiende la idea de la «feminización» de los procesos de control social, en el sentido de que "todos estemos hoy construidos como tradicionalmente han sido construidas las mujeres: víctimas y vulnerables» (Pitch, 2009: 21). Sería, por tanto, de gran interés analizar en qué medida esa imagen que devuelven los MdR sobre las personas encarceladas, en el marco de las «criminologías del yo» y de las «criminologías del otro", así como de otras prácticas penitenciarias modificadas en el contexto del neoliberalismo, y en confluencia con la estrategia que consagra y refuerza un modelo de domesticidad «revisitado», está suponiendo una cierta «feminización» del tratamiento en el conjunto del sistema penitenciario español. Con este ejercicio, se buscaría, de un lado, no cometer errores pasados al obviar en las explicaciones generales de la penalidad y el castigo las particularidades del encarcelamiento femenino y, de otro, contribuir a una más amplia incorporación de la perspectiva de género en el estudio de las cárceles españolas, a partir del análisis de la construcción de las masculinidades en el marco de un sistema heteropatriarcal, tema muy poco explorado hasta la actualidad.

\section{Referencias bibliográficas}

Almeda, Elisabet (2002). Corregir y castigar: El ayer y hoy de las cárceles de mujeres. Barcelona: Edicions Bellaterra.

- (2003). Mujeres encarceladas. Barcelona: Ariel.

Almeda, Elisabet y Bodelón, Encarna (eds.) (2007). Mujeres y castigo: Un enfoque socio-jurídico y de género. Madrid: Dykinson. 
Ballesteros, Ana (2010). «Cárceles y mujeres. Centros penitenciarios en España: Desigualdad y reproducción de roles de género». Trabajo final para la obtención del máster en Igualdad y Género en el Ámbito Público y Privado. Universidad Jaume I de Castellón.

- (2014). «Respectful Modules (Módulos de respeto) from a gender perspective: Research approach and preliminary results». Comunicación presentada en el 14th Annual Conference of the European Society of Criminology (ESC). Praga, del 10 al 13 de septiembre.

Ballesteros, Ana y Almeda, Elisabet (2015). «Políticas de igualdad en las cárceles del siglo xxI: Avances, retrocesos y retos en la práctica del encarcelamiento femenino". Praxis Sociológica, 19, 161-186.

Bertrand, Marie-Andrée (1998). Prisons pour femmes. Montréal: Les Éditions du Méridien.

Bosworth, Mary (1999). Engendering resistance: Agency and power in Women's prisons. Aldershot: Ashgate.

- (2000). «Confining femininity: A history of gender, power and imprisonment». Theoretical Criminology [en línea], 4 (3), 265-284. <http://dx.doi.org/10.1177/1362480600004003002>.

- (2007). "Creating the responsible prisoner: Federal admission and orientation packs». Punishment and Society [en línea], 9 (1), 67-85. <http://dx.doi.org/10.1177/1462474507070553>.

Bosworth, Mary y Carrabine, Eamonn (2001). «Reassessing resistance: Race, gender and sexuality in prison». Punishment and Society [en línea], 3 (4), 501-515. <http://dx.doi.org/10.1177/14624740122228393>.

Campelli, Enzo et al. (1992). Donne in carcere. Milán: Feltrinelli.

Carlen, Pat (1985). «Introduction». En: Carlen, Pat et al. Criminal Women. Oxford: Basil Blackwell.

Carlen, Pat y Tchaikovsky, Chris (1996). "Women's Imprisonment in England at the End of the Twentieth Century: Legitimacy, Realities and Utopias». En: MatThews, Roger y Francis, Paul (eds.). Prison 2000. Londres: Macmillan.

Carlen, Pat y Worrall, Anne (2004). Analysing women's imprisonment. Londres: Willan Pub.

Castillo, Joaquina y Ruiz, Marta J. (2010). «Mujeres extranjeras en prisiones españolas: El caso andaluz». Revista Internacional de Sociología [en línea], 68 (2), 473-498. <http://dx.doi.org/10.3989/ris.2008.05.15>.

Cendón, José Manuel; Belinchón, Esteban y García, Henar (2011). Módulos de Respeto: Manual de aplicación. Madrid: Secretaría General de Instituciones Penitenciarias. Ministerio del Interior.

Chesney-Lind, Meda y Morash, Merry (2013). «Transformative Feminist Criminology: A Critical Re-thinking of a Discipline». Critical Criminology [en línea], 21 (3), 287-304.

<http://dx.doi.org/10.1007/s10612-013-9187-2>.

Comité Europeo para la Prevención de la Tortura y de todos los tratos InHUMANOS Y DEgRADANTES (CPT) (2013). Informe al gobierno español sobre la visita a España. Estrasburgo: CPT.

De Miguel, Estíbaliz (2016). Relaciones amorosas de las mujeres encarceladas. Bilbao: Universidad del País Vasco.

Defensor del Pueblo Andaluz (2006). Mujeres privadas de libertad en centros penitenciarios de Andalucía. Sevilla: Defensor del Pueblo Andaluz. 
Dobash, Russel P.; Dobash, Rebecca E.; GutTeridge, Sue (1986). The Imprisonment Of Women. Oxford: Basil Blackwell.

EQUipo Barañí (2001). Mujeres gitanas y sistema penal. Madrid: Metyel.

- (2007). «Apuntes sobre la situación de la comunidad gitana en la sociedad española: Mitos y realidades que influyen en la criminación de las mujeres gitanas». En: Almeda, Elisabet y Bodelón, Encarna. Mujeres y castigo: Un enfoque socio-jurídico y de género. Madrid: Dykinson.

Faccioli, Franca (1987). «I comando difficile: Considerazioni su donne e controllo nel carcere femninile». En: PITCH, Tamar (eds). Diritto e rovescio. Nápoles: ESI.

Foucault, Michel (1975). Vigilar y castigar: Nacimiento de la prisión. Madrid: Siglo XXI. 1979.

Francés, Paz y Serrano, Guadalupe (2011). Mujeres en prisión: Voces desde dentro del centro penitenciario de Pamplona. Pamplona: Salhaketa.

Garland, David (1996). "The limits of the Sovereign State: Strategies of Crime Control in Contemporary Society». The British Journal of Criminology [en línea], 36 (4), 445-471. <http://dx.doi.org/10.1093/oxfordjournals.bjc.a014105>.

- (2001). La cultura del control: Crimen y orden social en la sociedad contemporánea. Barcelona: Gedisa.

GeA, María José; Domínguez, Mario y Sádaba, Igor (2014). Una condena compartida: Un estudio de caso sobre el control penal. Madrid: Tierradenadie Editores.

Gelsthorpe, Loraine (1989). Sexism and the Female Offender. Aldershot: Gower.

- (2002). «Feminism and criminology». En: Maguire, Mark; Morgan, Rod y Reiner, Robert (eds.). The Oxford Handbook of Criminology. 3a ed. Oxford: Oxford University Press.

Giallombardo, Rose (1974). The Social World of Imprisoned Girls. Nueva York: Wiley.

Hannah-Moffat, Kelly (2000). "Prisons that empower: Neo-liberal Governance in Canadian Women's Prisons». British Journal of Criminology [en línea], 40 (3), 510-531. <http://dx.doi.org/10.1093/bjc/40.3.510>.

- (2001). Punishment in disguise: Penal Governance and Federal Imprisonment of Women in Canada. Toronto: University of Toronto Press.

Heidensohn, Frances M. (1985). Women and crime. Londres: Macmillan.

Heidensohn, Frances y Gelsthorpe, Loraine (2007). «Gender and crime». En: Maguire, Mark; Morgan, Rod y Reiner, Robert (eds.). The Oxford Handbook of Criminology. 4a ed. Oxford: Oxford University Press.

Hernández, Fernando (2013). «Cárceles de mujeres del novecientos: Una práctica de siglos». En: Oliver, Pedro (coord.). El siglo de los castigos: Prisión y formas carcelarias en la España del siglo XX. Madrid: Anthropos.

Igareda, Noelia (2007). «Mujeres en prisión». En: Cerezo, Ana Isabel y García, Elisa (coords.). La prisión en España: Una perspectiva criminológica. Granada: Editorial Comares.

Manzanos, César y Balmaseda, Juana (2003). Situación de las mujeres en las cárceles del País Vasco. Donostia-San Sebastián: Gobierno Vasco.

Mapelli, Borja (dir.) (2012). Mujeres en las cárceles de Andalucía. Madrid: Dykinson.

Mapelli, Borja; Herrera, Myriam y Sordi, Bárbara (2013). "La exclusión de las excluidas. ¿Atiende el sistema penitenciario a las necesidades de género?: Una visión andaluza». Estudios Penales y Criminológicos, 33, 59-95. 
Melossi, Darío y Pavarini, Massimo (1987). Cárcel y fábrica: Los orígenes del sistema penitenciario (siglos XVI-XIX). México: Siglo XXI.

Miralles, Teresa (1983). "La mujer: El control informal». En: Bergalli, Roberto y Bustos, Juan (dir.) (1983). El pensamiento criminológico. Volumen II. Estado y control. Bogotá: Editorial Temis.

Miranda, María Jesús y Martín, María Teresa (2007). «Mujeres no nacionales en prisión». En: Almeda, Elisabet y Bodelón, Encarna (eds.). Mujeres y castigo: Un enfoque socio-jurídico y de género. Madrid: Dykinson.

Miranda, María Jesús; Martín, María Teresa y Vega, Cristina (eds.) (2005). Delitos $y$ fronteras. Madrid: Editorial Complutense.

NAREDO, María (2004). "¿Qué nos enseñan las reclusas?: La criminalización de la pobreza desde la situación de reclusas extranjeras y gitanas». Humanismo y Trabajo Social, 3, 67-94.

Nash, Mary (2004). Mujeres en el mundo: Historia, retos y movimientos. Madrid: Alianza Editorial.

Piтch, Tamar (1987). Diritto e rovescio: Studi sulle donne e il controllo sociale. Nápoles: Edizione Scientifiche Italiane.

- (2009). La sociedad de la prevención. Buenos Aires: Ad-Hoc.

Proyecto MIP (2005). Mujeres, integración y prisión: Un análisis de los procesos de integración sociolaboral de las mujeres presas en Europa. Barcelona: Aurea Editores.

RenzetTi, Claire M. (2013). Feminist criminology. Londres: Routledge.

Rivas, Natalia; Almeda, Elisabet y Bodelón, Encarna (2005). Rastreando lo invisible. Mujeres extranjeras en las cárceles. Rubí (Barcelona): Anthropos.

Secretaría General de Instituciones Penitenciarias (2009). Programa de acciones para la igualdad entre mujeres y hombres en el ámbito penitenciario. Madrid: Ministerio del Interior.

- (2011). Circular 18/2011 de Niveles de intervención en Módulos de Respeto de 10/11/2011 de la SGIIPP del Ministerio del Interior. Madrid: Ministerio del Interior.

Smart, Carol (1976). Women, Crime and Criminology. Londres: Routledge \& Kegan Paul.

Val, Consuelo del y Viedma, Antonio (eds.) (2012). Condenadas a la desigualdad: Sistema de indicadores de discriminación penitenciaria. Barcelona: Icaria.

YAGÜE, Concepción (2006). Madres en prisión: Historia de las cárceles de mujeres a través de su vertiente maternal. Granada: Comares.

- (2012). «Políticas de género y prisión en España». En: VAL, Consuelo del y VIedMA, Antonio (eds.) (2012). Condenadas a la desigualdad: Sistema de indicadores de discriminación penitenciaria. Barcelona: Icaria. 